\title{
Estimation of plant height and yield based on UAV imagery in faba bean (Vicia faba L.)
}

\author{
Yishan $\mathrm{Ji}^{1 \dagger}$, Zhen Chen ${ }^{2 \dagger}$, Qian Cheng ${ }^{2}$, Rong Liu' ${ }^{1}$, Mengwei Li ${ }^{1}$, Xin Yan ${ }^{1}$, Guan Li ${ }^{1}$, Dong Wang ${ }^{1}$, Li Fu ${ }^{1}$, Yu Ma ${ }^{3}$, \\ Xiuliang $\mathrm{Jin}^{1 *}$, Xuxiao Zong ${ }^{1 *}$ and Tao Yang ${ }^{1 *}$ (D)
}

\begin{abstract}
Background: Faba bean is an important legume crop in the world. Plant height and yield are important traits for crop improvement. The traditional plant height and yield measurement are labor intensive and time consuming. Therefore, it is essential to estimate these two parameters rapidly and efficiently. The purpose of this study was to provide an alternative way to accurately identify and evaluate faba bean germplasm and breeding materials.

Results: The results showed that $80 \%$ of the maximum plant height extracted from two-dimensional red-greenblue (2D-RGB) images had the best fitting degree with the ground measured values, with the coefficient of determination $\left(R^{2}\right)$, root-mean-square error (RMSE), and normalized root-mean-square error (NRMSE) were 0.9915, $1.4411 \mathrm{~cm}$ and $5.02 \%$, respectively. In terms of yield estimation, support vector machines (SVM) showed the best performance $\left(R^{2}=0.7238, \mathrm{RMSE}=823.54 \mathrm{~kg} \mathrm{ha}^{-1}, \mathrm{NRMSE}=18.38 \%\right)$, followed by random forests (RF) and decision trees (DT).

Conclusion: The results of this study indicated that it is feasible to monitor the plant height of faba bean during the whole growth period based on UAV imagery. Furthermore, the machine learning algorithms can estimate the yield of faba bean reasonably with the multiple time points data of plant height.
\end{abstract}

Keywords: Faba bean (Vicia faba L.), Unmanned aerial vehicle (UAV), Plant height, Yield estimation, Machine learning

\section{Background}

Faba bean (Vicia faba L.) is a cool-season legume crop, planted worldwide as a protein source of food, livestock feed, vegetables and industrial raw materials $[1,2]$. According to the FAO statistical data (FAOSTAT; http:// www.fao.org/), there were 71 countries and regions in the world planting dry faba bean in 2019. The harvesting area was $2,577,201$ square hectometers $\left(\mathrm{hm}^{2}\right)$, and the total production reached $5,431,503$ tons $(t)$, while the harvesting area of China was $839,618 \mathrm{hm}^{2}$ and the production was $1,740,945 \mathrm{t}$, respectively. Therefore, China is the most

\footnotetext{
*Correspondence: jinxiuliang@caas.cn; zongxuxiao@caas.cn; yangtao02@caas.cn

${ }^{\dagger}$ Yishan Ji and Zhen Chen contributed equally to this work ${ }^{1}$ National Key Facility for Crop Gene Resources and Genetic

Improvement/Institute of Crop Sciences, Chinese Academy of Agricultural Sciences, Haidian District, Beijing 100081, China

Full list of author information is available at the end of the article
}

important producer globally [3]. Faba bean is rich in protein, carbohydrates, minerals and vitamins [4]. Especially, the protein content of dry faba bean ranges from 20.3 to $41 \%$, with an average of $27.6 \%$, which is higher than pea, mungbean, cowpea and other legumes [5].

Plant height is a vital growth indicator of crops, which is related to plant architecture, lodging resistance and yield performance [6-8]. Early yield estimation is crucial for agricultural practices and it could provide farmers with field management decisions such as fertilization, irrigation and pesticide application [9]. Using early-season data for yield estimation could not only reduce resource input and environmental pollution, but also increase crop yield and subsequent profits $[10,11]$. Therefore, we need access to crop height and yield efficiently and non-destructively [12-14]. The traditional method for plant height measurement through measuring the vertical distance from the ground to the top of the 
main stem in the natural state by the ruler [15] is laborconsuming, low throughput, destructive and prone to errors in the sampling. Moreover, plant height obtained by sampling several single plants is insufficient to represent the variations of all plants within the field $[16,17]$.

With the development of unmanned aerial vehicle (UAV) platform and miniaturization of sensors, it provides an alternative approach for crop height measurement [18]. UAV remote sensing technology is based on the platform of UAV and different sensors, which has the advantages of convenient operation, high flexibility, strong adaptability and low cost, therefore it is booming in agriculture research community [19-21].

RGB camera [22, 23], multispectral or hyperspectral camera [24], lidar $[25,26]$ and ultrasonic sensors [27, 28] have been applied on the UAV platform. These highthroughput phenotyping platforms have been implemented in many crops such as maize [29, 30], wheat $[31,32]$, rice [33, 34], sorghum [35, 36], soybean [37] in terms of plant height study. However, there was no report for faba bean. In previous studies, Han et al. [38] used the high-resolution RGB camera based on UAV platform to access to the multi-temporal images of corn in the field. Then plant height data was extracted by threedimensional reconstruction point cloud model and they found that the extracted plant height was highly correlated with that of manual measurement. Holman et al. [39] developed a rapid and accurate method for extracting plant height, and compared it to the standard field measurement $\left(R^{2} \geq 0.77, R M S E \leq 0.07 \mathrm{~m}\right)$. Demir et al. [40] filtered a digital surface model to derive the plant height, and compared the results with field measurement (Mean $=4.66 \mathrm{~cm}$, Median $=3.75 \mathrm{~cm}$, Standard Deviation $=13.78 \mathrm{~cm}$ ).

Various methods have been proposed and applied to crop yield estimation, such as crop growth models, remote sensing data, and crop growth models coupled with environmental factors. Jin et al. [41] developed a winter wheat yield estimation method by combining AquaCrop model with optical and radar imaging data using the position and orientation system algorithm, which resulted in highly correlations between predicted and measured yield. Tao et al. [42] estimated the yield of winter wheat by using three regression methods with variables of spectral indices, plant height extracted from UAV hyperspectral images and the ground-measured plant height. Gilliot et al. [43] showed the potential of predicting maize yield based on the plant height extracted from UAV imagery, which would be better for variability analysis in the field trials. Feng et al. [44] performed an in-season alfalfa yield estimation using an ensemble machine learning model, and the results demonstrated the efficacy of the proposed ensemble model. Sun et al. [45] developed six mainstream machine learning models to estimate the potato tuber yield and obtained satisfactory estimation results, which demonstrated the potential of combining hyperspectral imagery with machine learning in yield estimation.

These studies explored the application of different sensors to obtain plant height data. Few of them compared the accuracy of extracting plant height from two-dimensional red-green-blue (2D-RGB), two-dimensional multispectral (2D-MS) and three-dimensional red-green-blue (3D-RGB) images. Furthermore, to our knowledge, the detection of estimating the faba bean yield based on machine learning algorithms has not been investigated so far in the literatures. Therefore, the aims of the current study were to (1) evaluate the relationship between the ground measured plant height and digital features extracted from UAV imagery, (2) explore the correlation between plant height and yield of faba bean in different time points, (3) evaluate the accuracy of faba bean yield estimation based on plant height by using three machine learning algorithms (SVM, RF and DT).

\section{Results}

Results of plant height extracted from UAV imagery

The faba bean plant height values extracted from three types of UAV imagery were compared with the ground measured values, and the results were shown in Fig. 1.

From Fig. 1, it showed that the plant height extracted based on 2D-RGB were all higher than the ground measured value $\left(R^{2}=0.9915\right.$, $\left.R M S E=8.05 \mathrm{~cm}\right)$, and the plant height extracted based on 2D-MS were almost all lower than the ground measured value $\left(R^{2}=0.9521\right.$, RMSE $=10.17 \mathrm{~cm}$ ), while the most of plant height extracted based on 3D-RGB were higher than the ground measured value, and a few were lower than it $\left(R^{2}=0.9369\right.$, $\left.R M S E=7.52 \mathrm{~cm}\right)$. The $R^{2}$ between the plant height extracted from these three types of UAV imagery and the ground measured values were all greater than 0.9 , which showed that the plant height extracted from the UAV imagery had a strong correlation with the ground measured value, and this method can be used to measure plant height in V.faba.

The correlation of plant height between the ground measurement and extraction from 2D-RGB UAV imagery was the strongest among these three types of UAV imagery, and the spatial distribution map of faba bean plant height in different time were shown in Fig. 2.

\section{Calibration of plant height values extracted from 2D-RGB, 2D-MS and 3D-RGB}

By comparing the plant height extracted from three types of UAV imagery with those measured on the ground, it was found that the maximum value of $R^{2}$ was $2 D-R G B$ 


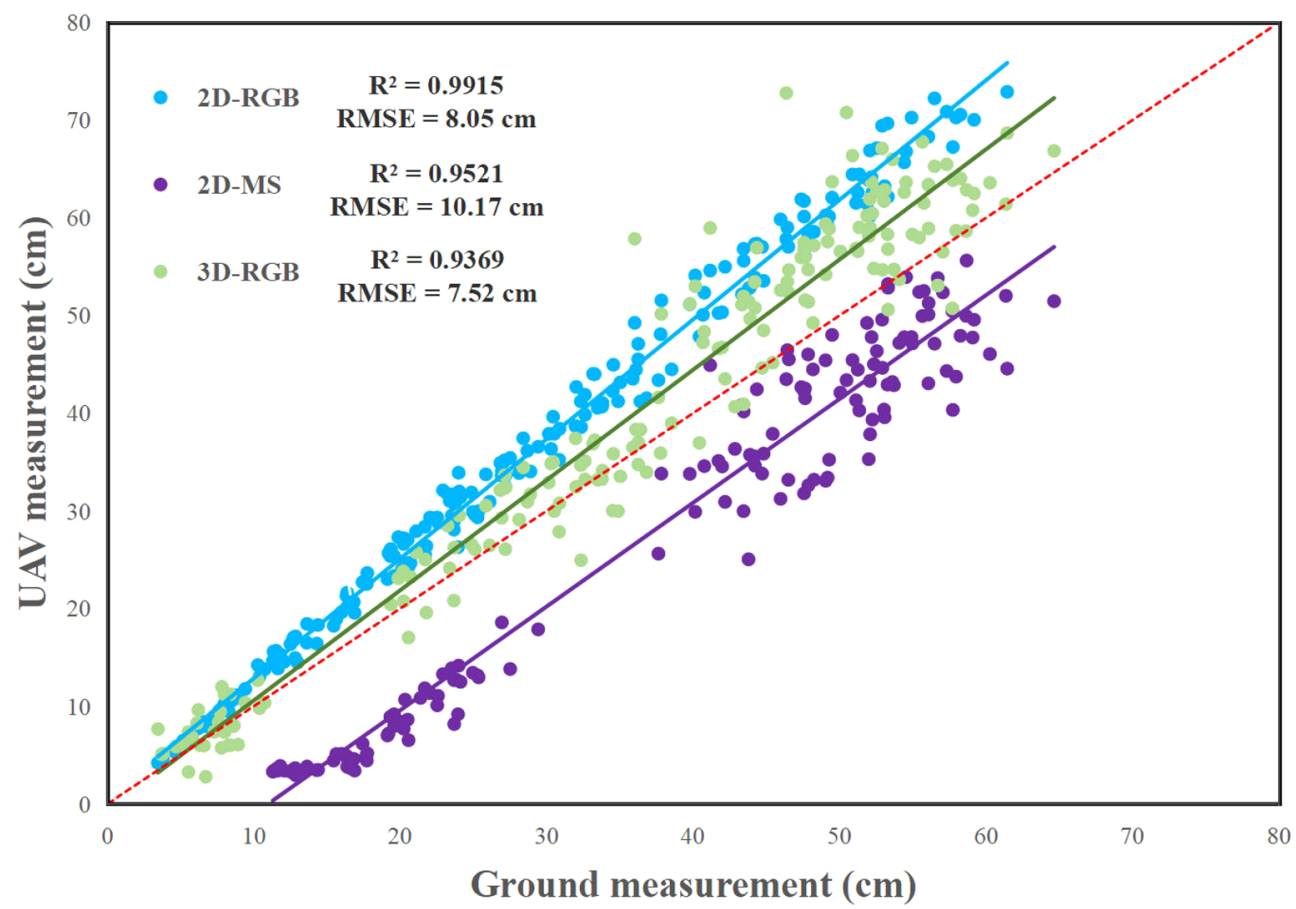

Fig. 1 Results of extracting faba bean plant height from three types of UAV imagery

(0.9915), followed by 2D-MS (0.952) and 3D-RGB (0.9399). The smallest value of RMSE was 3D-RGB $(7.52 \mathrm{~cm})$, followed by 2D-RGB $(8.05 \mathrm{~cm})$ and 2D-MS $(10.17 \mathrm{~cm})$. The smallest value of NRMSE was 3D-RGB (20.30\%), followed by 2D-MS (26.97\%) and 2D-RGB (28.05\%). According to these evaluation indicators, it could be found that the extracted data with high coefficient of determination $\left(R^{2}\right)$ had relatively large errors (RMSE, NRMSE), while the data with small errors had relatively low coefficient of determination, so it was difficult to judge which type of UAV imagery was the most appropriate one for extracting the faba bean plant height in this study. Therefore, the plant height values extracted from three types of UAV imagery were calibrated in proportion of $70 \% \sim 100 \%$ (Table 1 ).

As presented in Table 1 , the $\mathrm{R}^{2}$ between UAV measurement and ground measurement did not increase. However, calibration did significantly reduce the RMSE and NRMSE. In 2D-RGB, $80 \%$ of plant height was the most optimum result, with the $\mathrm{R}^{2}$ of 0.9915 , RMSE of $1.44 \mathrm{~cm}$, NRMSE of $5.02 \%$, and the fitting equation was $y=0.9796 x+0.4909$. In 2D-MS, $100 \%$ plant height was the most optimum result, with $\mathrm{R}^{2}$ of 0.952 , RMSE of $10.17 \mathrm{~cm}$, NRMSE of $26.97 \%$, and the fitting equation was $y=1.0624 x-11.662$. In 3D-RGB, $90 \%$ of plant height was the most optimum result, with $\mathrm{R}^{2}$ of 0.9399 , RMSE of $5.23 \mathrm{~cm}$, NRMSE of $14.12 \%$, and the fitting equation was $y=1.1934 x-7.8951$. In this study, from the comparison of these three optimal results, $80 \%$ of plant height values extracted from 2D-RGB UAV imagery was the most suitable for monitoring plant height during the whole growth period of faba bean.

\section{Comparison of the most suitable plant height and ground measurement}

The $80 \%$ of plant height values extracted from 2D-RGB UAV imagery was compared with the ground measured values, which was represented by box-plot (Fig. 3).

As Fig. 3 showed, during the whole growth period of faba bean, the average plant height extracted from UAV imagery was almost consistent with that of the ground measured. Meanwhile, the dynamic changes of plant height were well represented by UAV measured. This implied that the 2D-RGB UAV imagery was effective in estimating the plant height in $V$. faba.

\section{Correlation analysis between plant height and yield in faba bean}

Pearson's correlation coefficients were initially estimated to verify the association between yield and the optimal plant height values at seven time points, and the results were shown in Fig. 4.

As presented in Fig. 4 that there was a strong correlation between plant height and yield at seven time points, ranged from 0.3 to 0.87 . Among them, D4 (20190622) had the highest correlation with yield, reaching 0.77 , and 


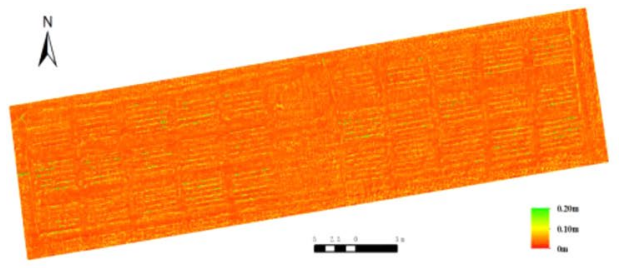

20190605

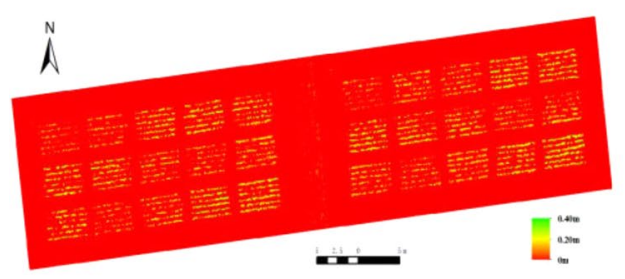

20190617

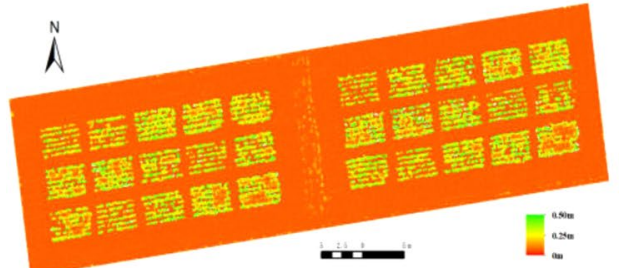

20190701

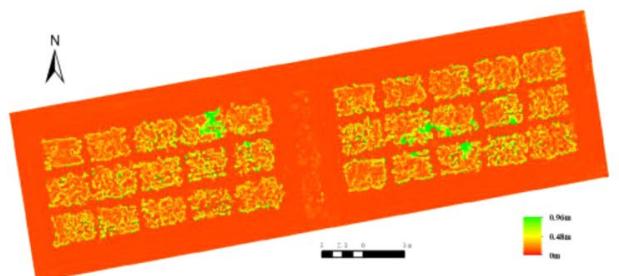

20190812

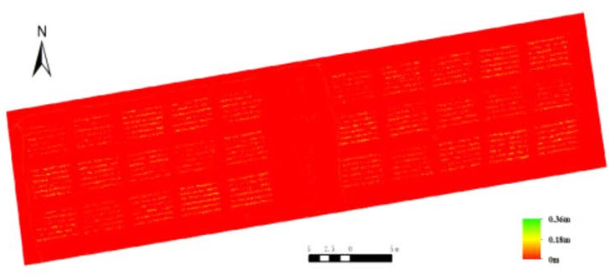

20190611

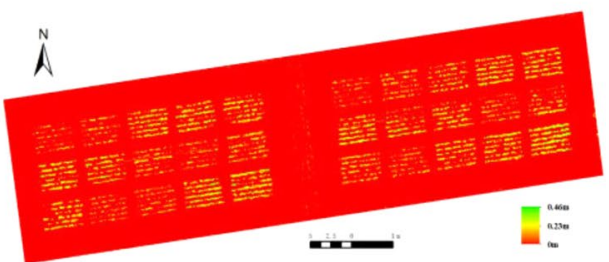

20190622

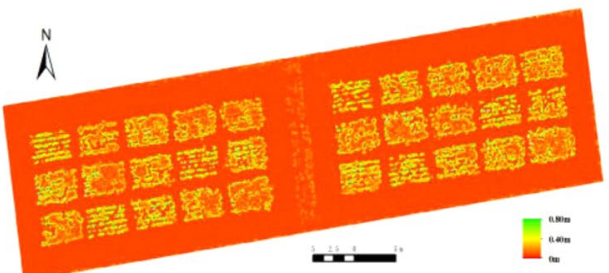

20190712

Fig. 2 Spatial distribution of faba bean plant height in different time

D7 (20190812) had the lowest correlation with yield, only 0.38 . Through the comparisons, it was found that the correlation coefficients between the two adjacent time points were higher than those between the cross-time points, among which the correlation coefficients between D3 (20190617) and D4 (20190622) were the highest (0.87), while the correlation coefficient between D1 (20190605) and D7 (20190812) was the lowest (0.3).

\section{Construction and validation of yield estimation model for faba bean}

The plant height data at different time points and combinations of different time points were selected to estimate the yield of faba bean by using SVM, RF and DT machine learning algorithms. The results were shown in Additional file 1: Table S1. In the SVMbased algorithm, the range of $\mathrm{R}^{2}$, RMSE and NRMSE was $0.1441 \sim 0.7238,823.54 \sim 1387.26 \mathrm{~kg} \mathrm{ha}^{-1}$ and
$18.38 \% \sim 30.96 \%$, respectively. The best estimation result was based on D1 + D2 + D4 + D7 sample, and the obtained $\mathrm{R}^{2}$ was 0.7238 , RMSE was $823.54 \mathrm{~kg} \mathrm{ha}^{-1}$ and NRMSE was $18.38 \%$. In the RF-based algorithm, the range of $\mathrm{R}^{2}$, RMSE and NRMSE was $0.1257 \sim 0.6573$, $877.06 \sim 1636.73 \mathrm{~kg} \mathrm{ha}{ }^{-1}$, and $19.57 \% \sim 36.53 \%$, respectively. The best estimation result was based on $\mathrm{D} 1+\mathrm{D} 4+\mathrm{D} 6$ sample, and the obtained $\mathrm{R}^{2}$ was 0.6573 , RMSE was $877.06 \mathrm{~kg} \mathrm{ha}^{-1}$ and NRMSE was $19.57 \%$. In the DT-based algorithm, the range of $\mathrm{R}^{2}, \mathrm{RMSE}$ and NRMSE was $0.1403 \sim 0.5971,923.24 \sim 1368.67 \mathrm{~kg} \mathrm{ha}^{-1}$ and $20.60 \% \sim 30.54 \%$, respectively. The best estimation result was based on D1 + D4 sample and D1 + D4 + D6 sample, and the obtained $\mathrm{R}^{2}$ was 0.5971 , RMSE was 923.24 $\mathrm{kg} \mathrm{ha}^{-1}$ and NRMSE was $20.60 \%$.

The estimated yield based on three machine learning algorithms were compared with measured yield, and the results were shown in the 1:1 line diagram 
of measured and estimated values (Fig. 5). It could be found that the estimated values of faba bean yield based on plant height was in good agreement with the measured values. The $R^{2}$ between the estimated and measured yield based on SVM algorithm was 0.6474 , RMSE was $838.61 \mathrm{~kg} \mathrm{ha}^{-1}$ and NRMSE was $18.71 \%$. The $\mathrm{R}^{2}$ between the estimated yield and measured yield based on RF algorithm was 0.5777, RMSE was $917.64 \mathrm{~kg} \mathrm{ha}^{-1}$ and NRMSE was $20.48 \%$. The $\mathrm{R}^{2}$ between the estimated yield and measured yield based on DT algorithm was 0.5097 , RMSE was $990.01 \mathrm{~kg} \mathrm{ha}^{-1}$ and NRMSE was $22.09 \%$.

\section{The yield estimation in different number of time points}

By comparing the estimation results of the three machine learning algorithms for faba bean yield under different number of time points (Table 2), it can be found that in the SVM-based algorithm, when the number of time points was 7 , the average $R^{2}$ was the highest $(0.5776)$ and the corresponding RMSE, NRMSE was $981.26 \mathrm{~kg} \mathrm{ha}^{-1}$, $21.90 \%$, respectively. In the RF-based algorithm, when the number of time points was 5 , the average $R^{2}$ was the highest (0.5004) and the corresponding RMSE, NRMSE was $990.55 \mathrm{~kg} \mathrm{ha}^{-1}, 22.11 \%$, respectively. In the

Table 1 Statistical results of plant height in different proportion

\begin{tabular}{|c|c|c|c|c|c|}
\hline Type & $\mathrm{PH} \%$ & $\mathrm{R}^{2}$ & $\begin{array}{l}\text { RMSE } \\
(\mathrm{cm})\end{array}$ & $\begin{array}{l}\text { NRMSE } \\
(\%)\end{array}$ & Fitting equation \\
\hline \multirow{7}{*}{$\begin{array}{l}2 \mathrm{D}- \\
\mathrm{RGB}\end{array}$} & $70 \%$ & 0.9915 & 4.45 & 15.51 & $y=0.8571 x+0.4299$ \\
\hline & $75 \%$ & 0.9915 & 2.62 & 9.12 & $y=0.9184 x+0.4606$ \\
\hline & $80 \%$ & 0.9915 & 1.44 & 5.02 & $y=0.9796 x+0.4909$ \\
\hline & $85 \%$ & 0.9915 & 2.34 & 8.15 & $y=1.0408 x+0.522$ \\
\hline & $90 \%$ & 0.9915 & 4.13 & 14.39 & $y=1.102 x+0.5527$ \\
\hline & $95 \%$ & 0.9915 & 6.07 & 21.15 & $y=1.1633 x+0.5834$ \\
\hline & $100 \%$ & 0.9915 & 8.05 & 28.05 & $y=1.2245 x+0.6141$ \\
\hline \multirow[t]{7}{*}{ 2D-MS } & $70 \%$ & 0.952 & 18.54 & 49.17 & $y=0.7437 x-8.1637$ \\
\hline & $75 \%$ & 0.952 & 17.02 & 45.12 & $y=0.7968 x-8.7468$ \\
\hline & $80 \%$ & 0.952 & 15.53 & 41.16 & $y=0.85 x-9.3299$ \\
\hline & $85 \%$ & 0.952 & 14.08 & 37.32 & $y=0.9031 x-9.913$ \\
\hline & $90 \%$ & 0.952 & 12.68 & 33.63 & $y=0.9562 x-10.496$ \\
\hline & $95 \%$ & 0.952 & 11.37 & 30.16 & $y=1.0093 x-11.079$ \\
\hline & $100 \%$ & 0.952 & 10.17 & 26.97 & $y=1.0624 x-11.662$ \\
\hline \multirow{7}{*}{$\begin{array}{l}\text { 3D- } \\
\text { RGB }\end{array}$} & $70 \%$ & 0.9399 & 9.49 & 25.62 & $y=0.9282 x-6.1406$ \\
\hline & $75 \%$ & 0.9399 & 7.69 & 20.78 & $y=0.9945 x-6.5793$ \\
\hline & $80 \%$ & 0.9399 & 6.20 & 16.76 & $y=1.0608 x-7.0179$ \\
\hline & $85 \%$ & 0.9399 & 5.28 & 14.26 & $y=1.1271 x-7.4565$ \\
\hline & $90 \%$ & 0.9399 & 5.23 & 14.12 & $y=1.1934 x-7.8951$ \\
\hline & $95 \%$ & 0.9399 & 6.07 & 16.40 & $y=1.2597 x-8.3337$ \\
\hline & $100 \%$ & 0.9399 & 7.52 & 20.30 & $y=1.326 x-8.7723$ \\
\hline
\end{tabular}

PH plant height, $R^{2}$ coefficient of determination, $R M S E$ root-mean-square error, NRMSE normalized root-mean-square error. The best result in terms of $R^{2}$, RMSE and NRMSE values were boldfaced
DT-based algorithm, when the number of time points was 4 , the average $\mathrm{R}^{2}$ was 0.5004 and the corresponding RMSE, NRMSE was $1026.93 \mathrm{~kg} \mathrm{ha}^{-1}, 22.92 \%$, respectively. Therefore, in the study of faba bean yield estimation based on different machine learning algorithms, the appropriate number of time points should be selected to obtain the best estimation results.

\section{Discussion \\ Extraction of imaged-based plant height feature in faba bean}

In recent years, the research of extracting crop plant height based on UAV remote sensing data has been widely used, and its applicability and accuracy have also been recognized by a large number of agricultural researchers. Lidar is an active sensor, which uses the laser pulse in the $600 \sim 1000 \mathrm{~nm}$ region to determine the distance to the object [46]. Compared with other sensors, laser radar is less affected by environmental conditions and has relatively high estimation accuracy for several crop phenotyping traits [47]. However, the price of lidar is generally high. In contrast, the RGB camera is affordable and easy to operate. Therefore, many researchers tend to use consumer-level sensors, but most of the previous studies were based on a single sensor data to extract plant height [30,32]. In this study, 2D-RGB, 2D-MS and 3D-RGB UAV imagery were collected respectively based on RGB camera and multispectral sensors, and it was found that the average plant height values of each plot extracted from these UAV imagery was lower than the ground measured values, which was consistent with the previous studies $[48,49]$. In view of the fact faba bean has branches, easy to lodging, and the plant height performance of each branch is quite different. Therefore, the maximum plant height of each plot and the percentage were used to compare and analyze with the ground measured values in this study. It was found that $80 \%$ of plant height extracted from 2D-RGB images was the most ideal for estimating the plant height, indicating that the plant height extracted by this method can be reasonably used to estimate the actual plant height of faba bean. In addition, by comparing these three types of data, it was found that the accuracy of plant height data was determined by the image resolution. Some previous studies have shown that high resolution images can improve the accuracy of the plant height model $[50,51]$.

\section{Yield estimation using UAV measurement of plant height in faba bean}

Plant height is one of the important agronomic traits in crop research, which can reflect crop growth status and is closely related to yield [52]. Yin et al. [53] took corn as the research object, collected plant height data from 


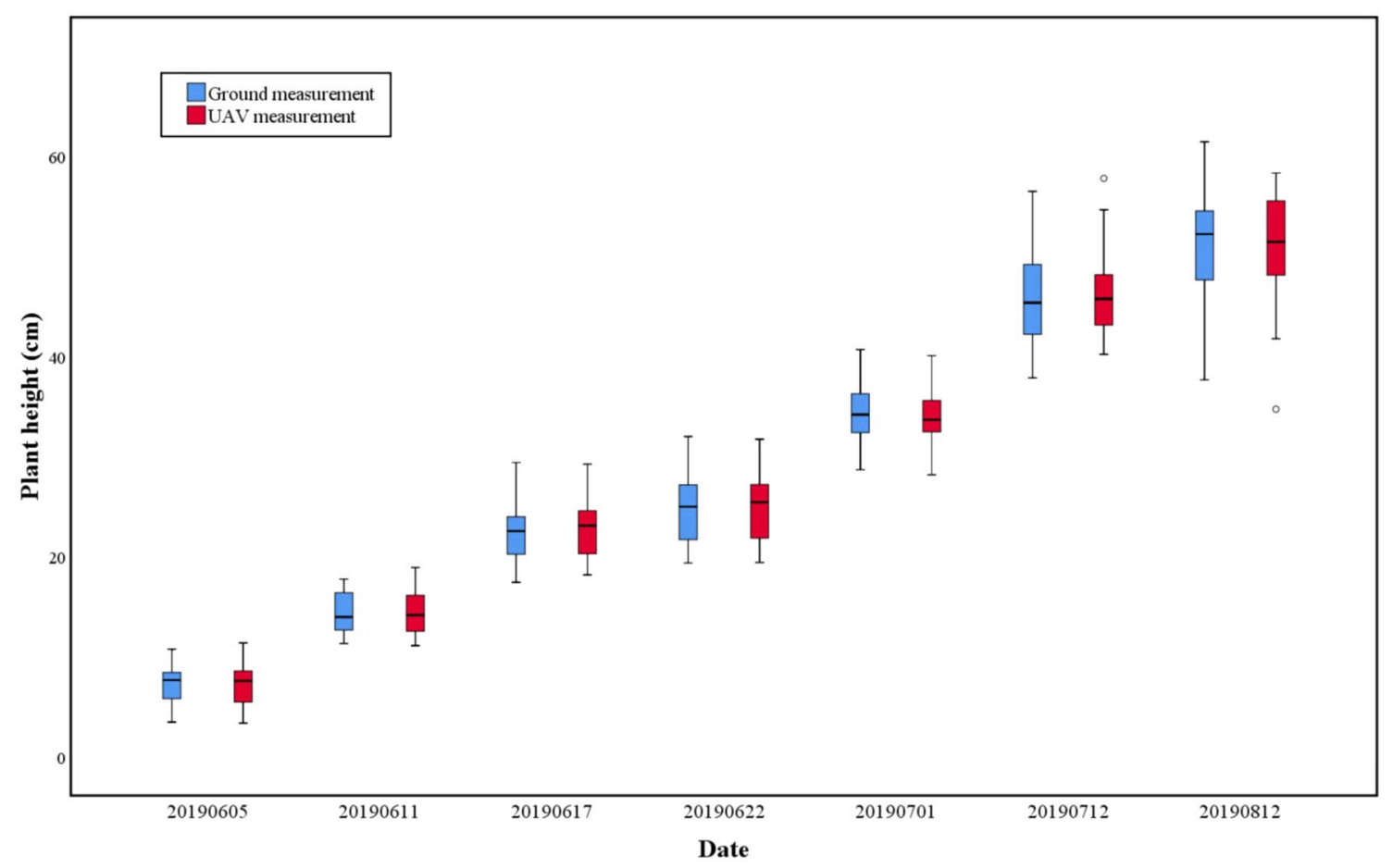

Fig. 3 Comparison of plant height between ground measurement and UAV measurement

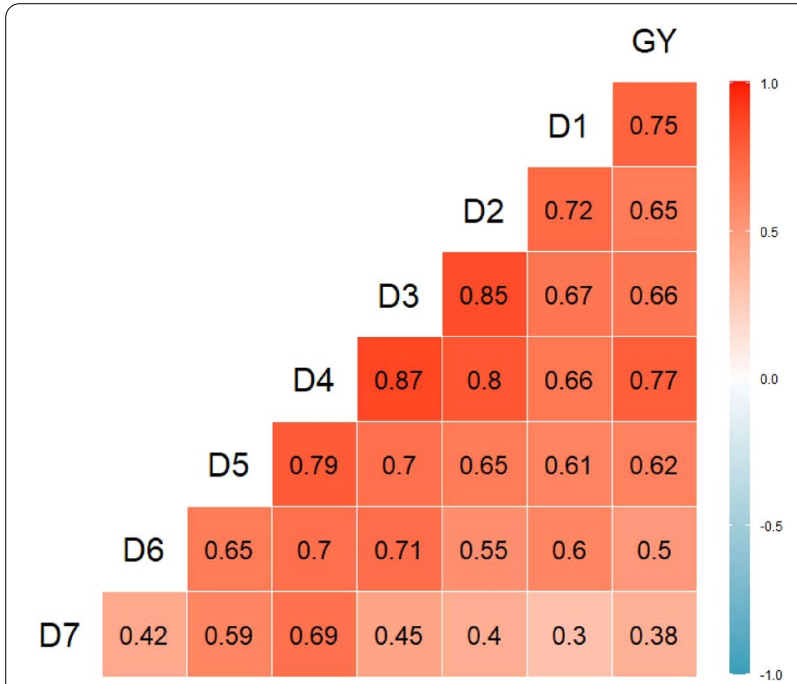

Fig. 4 Correlation map between yield and plant height in different time. GY: Grain yield; D1: Date 1 (20,190,605); D2: Date $2(20,190,611)$; D3: Date $3(20,190,617) ;$ D4: Date 4 (20,190,622); D5: Date 5 $(20,190,701) ;$ D6: Date 6 (20,190,712); D7: Date $7(20,190,812)$

2008 to 2010 at three time points V6, V10 and V12 respectively, and estimated annual corn yield based on the collected data. The obtained $R^{2}$ range was $0.32-$ 0.87 , among them, V10 $\left(R^{2} \geq 0.54\right)$ and V12 $\left(R^{2} \geq 0.69\right)$ were considered to be able to estimate the corn yield.
Other prior studies have addressed the importance of plant height in yield estimation $[54,55]$, but most of them were based on single time point plant height data to estimate yield and analyze the accuracy of its estimation. In this study, the yield of faba bean was estimated not only based on single time point plant height data, but also based on multiple time points combination of plant height data. The results showed that the single time point plant height could be used for estimation of faba bean yield, but its estimation effect was poor. When estimating faba bean yield based on multiple time points plant height, it was found that the estimation effect would be significantly improved, and the $\mathrm{R}^{2}$ of the best estimation model increased by 0.1252 , RMSE and NRMSE decreased $126.83 \mathrm{~kg} \mathrm{ha}^{-1}$ and $2.83 \%$, respectively. The results also showed that the correlation coefficients between the plant height and yield at early growth stage (D1, D2) and middle growth stage (D3, D4, D5) were higher than the late growth stage (D6, D7) in this study. It could be attributed to the fact that the plant main stem height at the late growth stage tended to be stable, but the yield was still in the accumulation process, leading to its estimates of the effect was not ideal. Therefore, in the process of estimating crop yield based on remote sensing data, the selection of model independent variables was crucial. In this study, only one year plant height data was used 


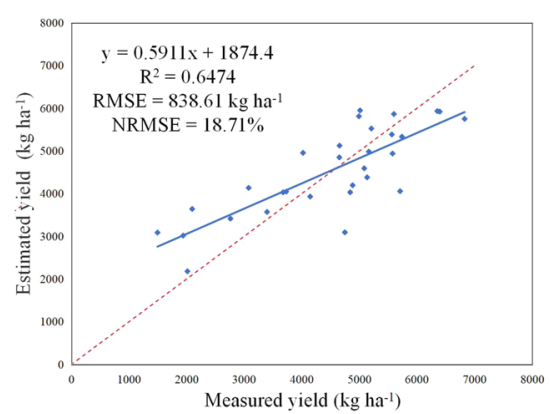

(a)

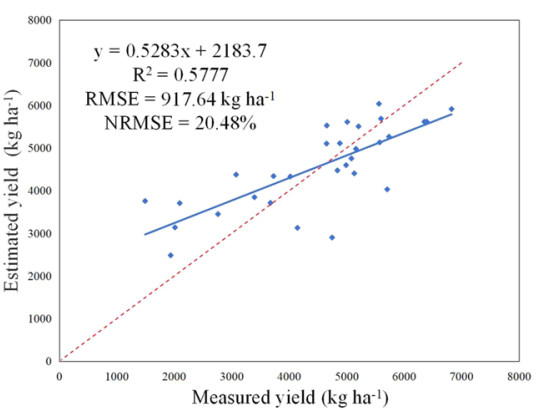

(b)

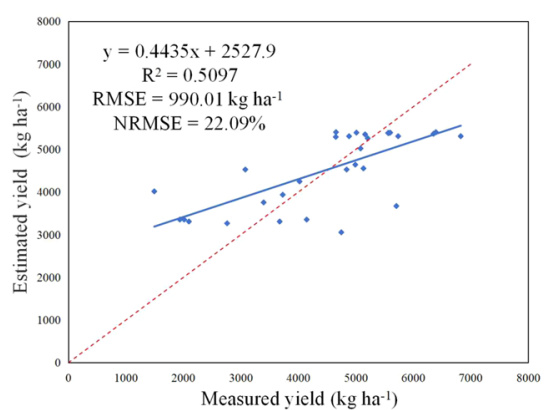

(c)

Fig. 5 Comparison of estimated yield and measured yield by machine learning algorithms. a Support Vector Machines; b Random Forests; $\mathbf{c}$ Decision Trees

to construct the yield model. In the future, it is necessary to further analyze and use the data of multiple years and multiple locations to obtain a more universal yield estimation model of faba bean.

\section{Performance of machine learning algorithms in faba bean yield estimation}

Machine learning algorithms has been widely used in crop yield estimation research, and the methods used in this study were in accordance with the previous applications where the machine learning algorithms were successfully applied and conducted [56]. In this study, three machine learning algorithms of SVM, RF and DT were respectively used to estimate the yield of faba bean. By comparing the estimation results generated using three machine learning algorithms (Additional file 1: Table S1), it could be found that the yield estimation effect of SVM was the best, followed by RF and DT. Guo et al. [57] found that SVM algorithm can improve the accuracy of crop yield estimation, which is consistent with the results of this study. RF method is suitable for large data sets and maintains high accuracy, but it usually leads to over-fitting phenomenon, resulting in slightly worse prediction results [58]. DT has poor predictive performance for data with time sequence or large data sets [59], which can explain its unsatisfactory estimation result of faba bean yield in this study. Multiple types of remote sensing data and advanced machine learning algorithms can be used to estimate the yield of faba bean in the future.

\section{Conclusions}

In the present study, three types of UAV imagery were used to extract the plant height of faba bean. The most optimum plant height values were used to estimate the yield of faba bean by using machine learning algorithms
(SVM, RF and DT). Overall, the results of this study presented that UAV imagery could provide accurate estimation of faba bean plant height and yield. This study will aid in finding a high-throughput and non-destructive way to estimate plant height and yield for faba bean, which would accelerate screening of germplasm and breeding materials.

\section{Methods \\ Research area and test design}

The research area was located in Guyuan Experimental Station of Institute of Crop Sciences (ICS), Chinese Academy of Agricultural Sciences (CAAS), Zhangjiakou city $\left(41^{\circ} 14^{\prime} 33^{\prime \prime}-41^{\circ} 56^{\prime} 55^{\prime \prime} \mathrm{N}, 114^{\circ} 50^{\prime} 388^{\prime \prime}-116^{\circ} 04^{\prime}\right.$ $09^{\prime \prime}$ E, with average altitude 1,536 m) in Hebei Province, China. It belongs to temperate continental grassland climate, annual average temperature is $1.6^{\circ} \mathrm{C}$, annual sunshine duration is $3,246 \mathrm{~h}$, the shortest sunshine duration is $2,616 \mathrm{~h}$, annual precipitation is $426 \mathrm{~mm}$ and the annual average frost-free period is $117 \mathrm{~d}$. The geographical location and UAV sampling sites of the research area was shown in Fig. 6. The research area was divided into two experimental parts, each of them has five varieties, GF13, GF22, GF44, GF45 and Maya. Three replicates were used with completely randomized trial design and each plot area was $4 \mathrm{~m} \times 2 \mathrm{~m}=8 \mathrm{~m}^{2}$. All cultivars were planted on April 18, 2019 at a depth of $5 \sim 8 \mathrm{~cm} .40$ seeds were planted in each row, and six rows in each plot. After emergence, manual weed extraction were conducted as needed, and no fertilizers were used during this study. In order to improve the accuracy of image stitching and plant height extraction, six ground control points (GCPs) were located in the field for later geometric correction and image registration. 
Table 2 Results of yield estimation in different number of time points

\begin{tabular}{|c|c|c|c|c|c|c|c|c|c|}
\hline \multirow{2}{*}{$\begin{array}{l}\text { Number of } \\
\text { Time Points }\end{array}$} & \multicolumn{3}{|l|}{ SVM } & \multicolumn{3}{|l|}{ RF } & \multicolumn{3}{|l|}{ DT } \\
\hline & $\mathrm{R}^{2}$ & RMSE $\left(\mathrm{kg} \mathrm{ha}^{-1}\right)$ & NRMSE (\%) & $\mathrm{R}^{2}$ & RMSE $\left(\mathrm{kg} \mathrm{ha}^{-1}\right)$ & NRMSE (\%) & $\overline{R^{2}}$ & RMSE $\left(\mathrm{kg} \mathrm{ha}^{-1}\right)$ & NRMSE (\%) \\
\hline 1 & 0.3296 & 1261.56 & 28.15 & 0.3683 & 1222.19 & 27.28 & 0.4018 & 1144.99 & 25.55 \\
\hline 2 & 0.3873 & 1175.28 & 26.23 & 0.4453 & 1092.13 & 24.37 & 0.4629 & 1068.64 & 23.85 \\
\hline 3 & 0.4785 & 1100.34 & 24.56 & 0.4877 & 1029.59 & 22.98 & 0.4937 & 1036.40 & 23.13 \\
\hline 4 & 0.5236 & 1052.76 & 23.49 & 0.4951 & 1003.83 & 22.40 & 0.5004 & 1026.93 & 22.92 \\
\hline 5 & 0.5512 & 994.17 & 22.71 & 0.4989 & 990.55 & 22.11 & 0.4975 & 1027.21 & 22.92 \\
\hline 6 & 0.5744 & 958.9 & 21.40 & 0.4955 & 984.11 & 21.96 & 0.4912 & 1031.83 & 23.03 \\
\hline 7 & 0.5776 & 981.26 & 21.90 & 0.4710 & 1008.70 & 22.51 & 0.4815 & 1038.23 & 23.17 \\
\hline
\end{tabular}

\section{Acquisition of ground data}

The ground data collected in this study included plant height and yield, and the acquisition time of plant height was consistent with UAV flight date, the acquisition time of yield was August 22, 2019. Ground-based plant height was obtained as follows: 12 representative plants were randomly selected in each plot. The ruler was used to measure the distance from the top to the ground of each plant under the natural state. And the average value of 12 plants was taken as the ground measured plant height for each plot. Ground-based yield was obtained as follows: all plants in each plot were harvested and dry grains were weighed as the yield for each plot.

\section{Acquisition and processing of UAV remote sensing data}

The acquisition and processing of UAV remote sensing data (Fig. 7) in this study mainly includes two stages: (1) Acquired UAV imagery based on flight planning software (DJI GS Pro, DJI Pilot, Pix4Dcapture); (2) Mosaiced UAV imagery in the structure from motion (SfM)-based software (Pix4DMapper) and then automatically generated digital surface model (DSM), digital terrain model (DTM) and Orthomosaic.

DJI Inspire 1 (SZ DJI Technology Co., Shenzhen, China), DJI Matrice 210 (SZ DJI Technology Co., Shenzhen, China) and DJI Phantom 4 (SZ DJI Technology Co., Shenzhen, China) were used to acquire UAV images of the experimental plots. The detailed parameters of three UAVs were shown in Table 3.

This study collected three types of UAV image data: 2D-RGB, 2D-MS and 3D-RGB. Zenmuse X3 camera carried by DJI Inspire 1 and Zenmuse X7 camera carried by DJI Matrice 210 were used to collect 2D-RGB images. RedEdge-MX sensor carried by DJI Matrice 210 was used to collect 2D-MS images. Phantom camera carried by DJI Phantom 4 was used to collect 3D-RGB images. The size of Zenmuse X3 camera is $1 / 2.3 "$ and the effective pixel is 12 million. The size of Zenmuse $\mathrm{X} 7$ camera is $151 \mathrm{~mm} \times 108 \mathrm{~mm} \times 132 \mathrm{~mm}$ and the effective pixel is 24 million. The size of Phantom camera is $1 / 2.3 "$ and the effective pixel is 12.4 million. The RedEdge-MX sensor has a weight of $232 \mathrm{~g}$ and a size of $87 \mathrm{~mm} \times 59 \mathrm{~mm} \times 45.4 \mathrm{~mm}$. It contains five bands:

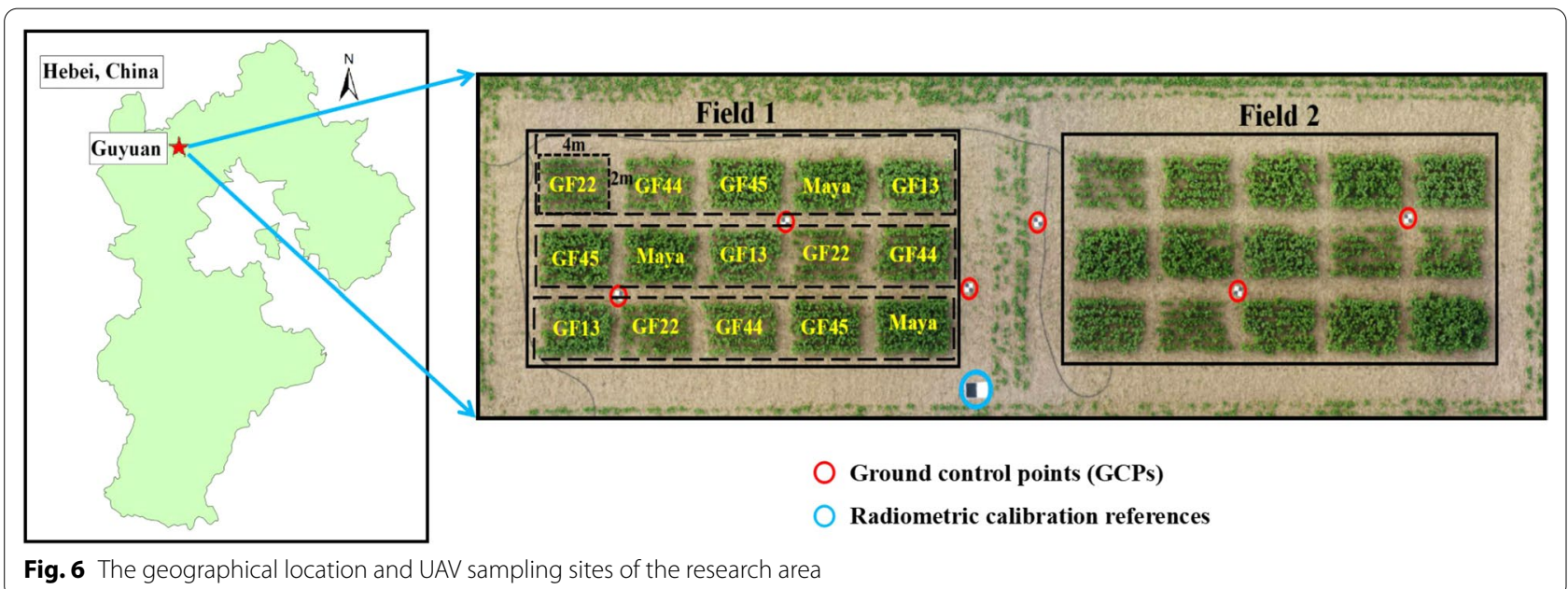




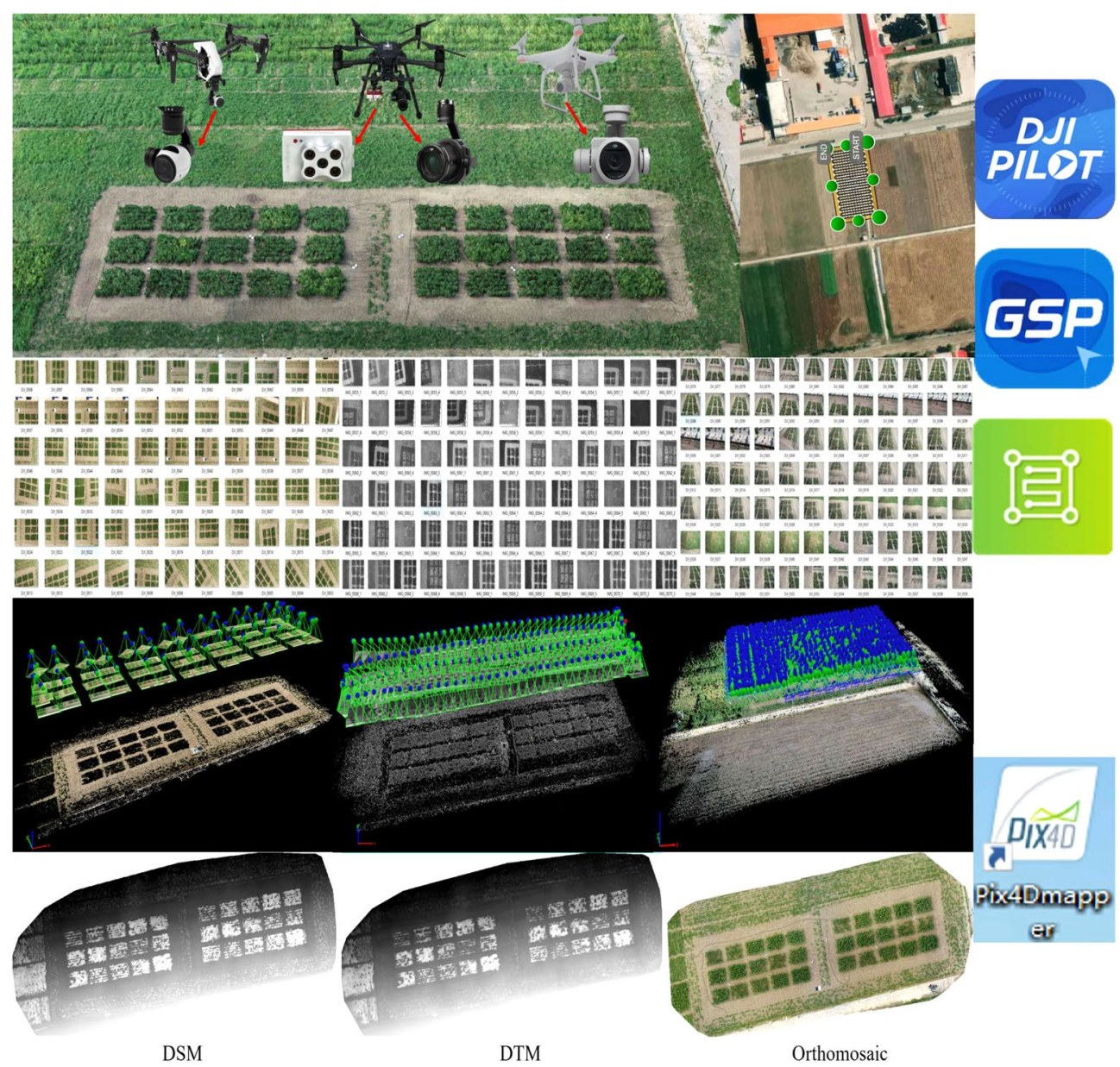

Fig. 7 Acquisition and processing of UAV remote sensing data

blue $(475 \mathrm{~nm})$, green $(560 \mathrm{~nm})$, red $(670 \mathrm{~nm})$, red-edge $(720 \mathrm{~nm})$ and near-infrared $(840 \mathrm{~nm})$, with the resolution of $1280 \times 960$.

The flights planning (Table 4) were applied under the conditions of cloudless and low wind speed.

The Pix4DMapper 4.4.12 software (Pix4D SA, Lausanne, Switzerland) [60, 61] was used to optimize the interior and exterior parameters of the images. A sparse dense cloud based on the structure-from-motion (SfM) technique and point clouds based on the multi-view stereo (MVS) with multiple control points collected were used. For 2D-RGB and 3D-RGB images, we imported the images into Pix4Dmapper, which would automatically read the position and orientation system (POS) data and the camera configuration information. Then, we set the number of matching feature points and the type

Table 3 Detailed parameters of three UAVs

\begin{tabular}{llll}
\hline Items & DJl inspire 1 & DJI matrice 210 & DJl phantom 4 \\
\hline Size/mm & $438 \times 451 \times 301$ & $883 \times 886 \times 398$ & $196 \times 289.5 \times 289.5$ \\
Body weight/g & 2935 & 4800 & 1380 \\
Wheelbase/mm & 581 & 643 & 350 \\
Endurance/min & 18 & 24 & 28 \\
Max speed/(m/s) & 22 & 17 & 20 \\
Flight planning software & DJl GS Pro & DJl Pilot & Pix4Dcapture \\
\hline
\end{tabular}


Table 4 Flights planning parameters for UAV imagery system

\begin{tabular}{|c|c|c|c|c|c|c|}
\hline Flight data & Type & Altitude & Forward overlap & Side overlap & UAV & Sensor \\
\hline $2019 / 6 / 5$ & 2D-RGB & $25 \mathrm{~m}$ & $85 \%$ & $80 \%$ & Dارl Matrice 210 & Zenmuse X7 \\
\hline 2019/6/11 & 2D-RGB & $25 \mathrm{~m}$ & $85 \%$ & $80 \%$ & Dاll Matrice 210 & Zenmuse X7 \\
\hline 2019/6/17 & 2D-RGB & $25 \mathrm{~m}$ & $85 \%$ & $80 \%$ & Dال Matrice 210 & Zenmuse X7 \\
\hline 2019/6/22 & 2D-RGB & $10 \mathrm{~m}$ & $85 \%$ & $80 \%$ & DJI Inspire 1 & Zenmuse X3 \\
\hline 2019/7/1 & 2D-RGB & $10 \mathrm{~m}$ & $85 \%$ & $80 \%$ & DJI Inspire 1 & Zenmuse X3 \\
\hline 2019/7/12 & 2D-RGB & $25 \mathrm{~m}$ & $85 \%$ & $80 \%$ & Dال Matrice 210 & Zenmuse X7 \\
\hline 2019/8/12 & 2D-RGB & $25 \mathrm{~m}$ & $85 \%$ & $80 \%$ & DJI Matrice 210 & Zenmuse X7 \\
\hline 2019/6/11 & 2D-MS & $25 \mathrm{~m}$ & $80 \%$ & $75 \%$ & Dار Matrice 210 & RedEdge-MX \\
\hline 2019/6/18 & 2D-MS & $25 \mathrm{~m}$ & $80 \%$ & $75 \%$ & Dارl Matrice 210 & RedEdge-MX \\
\hline 2019/7/12 & 2D-MS & $25 \mathrm{~m}$ & $80 \%$ & $75 \%$ & DIl Matrice 210 & RedEdge-MX \\
\hline 2019/8/6 & 2D-MS & $25 \mathrm{~m}$ & $80 \%$ & $75 \%$ & Dارl Matrice 210 & RedEdge-MX \\
\hline 2019/8/12 & 2D-MS & $25 \mathrm{~m}$ & $80 \%$ & $75 \%$ & DIl Matrice 210 & RedEdge-MX \\
\hline 2019/6/10 & 3D-RGB & $10 \mathrm{~m}$ & $90 \%$ & $85 \%$ & DI Phantom 4 & Phantom camera \\
\hline 2019/6/23 & 3D-RGB & $10 \mathrm{~m}$ & $90 \%$ & $85 \%$ & Dار Phantom 4 & Phantom camera \\
\hline 2019/6/30 & 3D-RGB & $10 \mathrm{~m}$ & $90 \%$ & $85 \%$ & Dار Phantom 4 & Phantom camera \\
\hline 2019/7/11 & 3D-RGB & $10 \mathrm{~m}$ & $90 \%$ & $85 \%$ & Dוر Phantom 4 & Phantom camera \\
\hline 2019/7/30 & 3D-RGB & $10 \mathrm{~m}$ & $90 \%$ & $85 \%$ & DI Phantom 4 & Phantom camera \\
\hline 2019/8/12 & 3D-RGB & $10 \mathrm{~m}$ & $90 \%$ & $85 \%$ & DJl Phantom 4 & Phantom camera \\
\hline
\end{tabular}

of output images in the process of stitching. Finally, the DSM, DTM and Orthomosaic were outputted in different files. For 2D-MS images, its processing steps were consistent with RGB images. Moreover, the stitching of multi-spectral images needs to use the calibrated reflectance panel image taken before UAV takeoff to carry out reflectance calibration.

\section{Extraction of plant height}

The DSM and DTM output files from Pix4DMapper software were used in Equation One to obtain crop surface model (CSM). Then CSM was used to extract the plant height data in each plot by using the ROI tool in the ENVI 5.3 software (ITT Visual Information Solutions, Boulder, CO, USA) [62], and the maximum plant height of each plot was selected for subsequent data processing. The calculation equation for Equation One was as follows:

$$
C S M=D S M-D T M
$$

\section{Machine learning algorithms}

SVM [63] is a widely used machine learning method for classification and regression analysis, which is based on the key concepts of statistical learning theory. The basic SVM model is a linear classifier, and the maximum interval is defined in the feature space. The maximum interval refers to those sample points closest or furthest from the hyperplane in the two types of sample points, whether the sample is low-dimensional or high-dimensional.
Since SVM can use kernel functions to convert highly nonlinear data into linearly separable data, so as to perform well on different data set. Overall, the SVM algorithm has great advantages in solving nonlinear, small sample and high dimensional problems. We conducted grid search based on radial basis kernel to determine the optimal values of hyperparameters $C$ and $\gamma$, which influence the accuracy and generalisation capabilities of the SVM [64].

RF [65] could be regarded as a machine learning model that combines a large number of regression trees. In regression modeling tasks, the main advantages of random forests are to minimize the risk of overfitting. At the same time, the importance of all predictive variables could be divided to evaluate the contribution of each predictive variable to the model, and then eliminate redundant variables. The key step to construct RF is to split the regression tree and take the average value of all trees as the prediction result of the final output. As Yang et al. [66] set in the research, we defined and optimized two hyperparameters in the random forest algorithm: one is the number of trees (ntree is 500), the other is the number of different variables for tree node splitting (mtry is one-third of the total number of variables).

DT [67] is a tree structure applied to classification and regression. A decision tree contains one root node, several internal nodes and several leaf nodes. The root node contains a full set of samples. Each internal node represents a test on an attribute, each branch represents a test output, and each leaf node represents a 
category. The decision-making process of the decision tree needs to start from the root node of the decision tree. The measured data are compared with the feature nodes of the decision tree, and the next comparison branch is selected according to the comparison results until the leaf node is used as the final decision result to complete the regression. We combined cross validation and grid search to select hyperparameters of DT.

\section{Statistical analysis}

Pearson correlation and machine learning algorithms (SVM, RF, DT) were calculated to check relationship and estimation between the plant height and yield, which were completed by RStudio 4.0.2 (RStudio, Inc. Boston, USA). In cross validation, the plant height values of a single time point or a combination of multiple time points were randomly divided into five parts. Four-fifths of the samples $(n=24$, plant height or yield of faba bean) were randomly selected as the modeling data set, and the other one-fifths of the samples $(n=6$, plant height or yield of faba bean) were used as the validation data set. The yield estimation model was verified by the sample data of validation set, and the final results were shown by the 1:1 plot of measured and estimated values.

To evaluate the model performance, three evaluation indicators were used to determine the accuracy of the yield estimation, namely the coefficient of determination $\left(R^{2}\right)$, root-mean-square error (RMSE), and normalized root-mean-square error (NRMSE) [48]. The calculation equations for these parameters are given as follows:

$$
\begin{aligned}
& R^{2}=1-\sum_{i=1}^{n}\left(x_{i}-y_{i}\right)^{2} / \sum_{i=1}^{n}\left(x_{i}-\bar{x}\right)^{2} \\
& R M S E=\sqrt{\sum_{i=1}^{n}\left(y_{i}-x_{i}\right)^{2} / n} \\
& N R M S E=R M S E / \bar{x}
\end{aligned}
$$

Where $x_{\mathrm{i}}$ is plant height or plant yield of faba bean, $\bar{x}$ is the average plant height or yield, $y_{i}$ is the plant height or yield predicted by the model, and $\mathrm{n}$ is the number of data points.

\footnotetext{
Abbreviations

2D-RGB: Two-dimensional red-green-blue; 2D-MS: Two-dimensional multispectral; 3D-RGB: Three-dimensional red-green-blue; UAV: Unmanned aerial vehicle; SVM: Support vector machines; RF: Random forests; DT: Decision trees; $R^{2}$ : Coefficient of determination; RMSE: Root-mean-square error; NRMSE: Normalized root-mean-square error; ICS: Institute of Crop Sciences; CAAS: Chinese Academy of Agricultural Sciences; GCPs: Ground control points; SfM: Structure from motion; DSM: Digital surface model; DTM: Digital terrain model; CSM: Crop surface model.
}

\section{Supplementary Information}

The online version contains supplementary material available at https://doi. org/10.1186/s13007-022-00861-7.

Additional file 1: Table S1. Results of yield estimation by machine learning algorithms.

\section{Acknowledgements}

We thank Dr. Yonggui Xiao for technological suggestion, and we also would like to thank the editors and the anonymous reviewers for their valuable comments and suggestions.

\section{Authors' contributions}

$\mathrm{XJ}, \mathrm{XZ}$ and TY designed this project. RL, ML, XY, GL, DW and LF conducted sample collections. $Y J$ and QC performed the experiment. $Y J$ and ZC finished data analyses and wrote the draft manuscript. $Y M, X J, X Z$, and TY revised the manuscript.

\section{Funding}

This work was support from the Fundamental Research Funds for the Institute Planning in Chinese Academy of Agricultural Sciences (No.120002), the Fundamental Research Funds for the Institute Planning in Chinese Academy of Agricultural Sciences (S2018QY02), China Agriculture Research System of MOF and MARA- Food Legumes (CARS-08), National Infrastructure for Crop Germplasm Resources project from the Ministry of Science and Technology of China (NICGR2019), Agricultural Science and Technology Innovation Program (ASTIP) in CAAS.

\section{Availability of data and materials}

The datasets used in this study is available from the corresponding author on reasonable request.

\section{Declarations}

Ethics approval and consent to participate

All authors read and approved the manuscript.

Consent for publication

All authors agreed to publish this manuscript.

\section{Competing interests}

The authors declare that they have no competing interests.

\section{Author details}

${ }^{1}$ National Key Facility for Crop Gene Resources and Genetic Improvement/ Institute of Crop Sciences, Chinese Academy of Agricultural Sciences, Haidian District, Beijing 100081, China. ${ }^{2}$ Institute of Farmland Irrigation, Chinese Academy of Agricultural Sciences, Xinxiang 453002, China. ${ }^{3}$ Department of Horticulture, Washington State University, Pullman, WA 99164, USA.

Received: 27 November 2021 Accepted: 20 February 2022

Published online: 05 March 2022

\section{References}

1. Murphy WM, Welch JG, Palmer RH, Gilman BE, Albers CW, Dugdale DT. Digestibilities of silages made from corn interplanted with soybean or fababean. J Dairy Sci. 1984;67(7):1532-4.

2. Kaur S, Pembleton LW, Cogan NOI, Savin KW, Leonforte T, Paull J, et al. Transcriptome sequencing of field pea and faba bean for discovery and validation of SSR genetic markers. BMC Genom. 2012;13(1):1-12.

3. Temesgen T, Keneni G, Sefera T, Jarso M. Yield stability and relationships among stability parameters in faba bean (Vicia faba L.) genotypes. Crop J. 2015;3(3):258-68.

4. Duc G, Bao S, Baum M, Redden B, Sadiki M, Suso MJ, et al. Diversity maintenance and use of Vicia faba L. genetic resources. F Crop Res. 2010;115(3):270-8. 
5. Crépon K. Nutritional value of legumes (pea and faba bean) and economics of their use. Recent Adv Anim Nutr. 2011;2006(1):331-66.

6. Gao Z, Wang Y, Tian G, Zhao Y, Li C, Cao Q, et al. Plant height and its relationship with yield in wheat under different irrigation regime. Irrig Sci. 2020;38(4):365-71.

7. Wang Y, Zhao J, Lu W, Deng D. Gibberellin in plant height control: old player, new story. Plant Cell Rep. 2017;36:391-8. https://doi.org/10.1007/ s00299-017-2104-5.

8. Li R, Li M, Ashraf U, Liu S, Zhang J. Exploring the relationships between yield and yield-related traits for rice varieties released in China from 1978 to 2017. Front Plant Sci. 2019;10:543.

9. Ramos APM, Osco LP, Furuya DEG, Gonçalves WN, Santana DC, Teodoro $L P R$, et al. A random forest ranking approach to predict yield in maize with uav-based vegetation spectral indices. Comput Electron Agric. 2020;178:105791.

10. McBratney A, Whelan B, Ancev T, Bouma J. Future directions of precision agriculture. Precis Agric. 2005;6(1):7-23.

11. Panda SS, Ames DP, Panigrahi S. Application of vegetation indices for agricultural crop yield prediction using neural network techniques. Remote Sens. 2010;2(3):673-96.

12. Hunt ER, Dean Hively W, Fujikawa SJ, Linden DS, Daughtry CST, McCarty GW. Acquisition of NIR-green-blue digital photographs from unmanned aircraft for crop monitoring. Remote Sens. 2010;2(1):290-305.

13. Poenaru V, Badea A, Cimpeanu SM, Irimescu A. Multi-temporal multispectral and radar remote sensing for agricultural monitoring in the braila plain. Agric Agric Sci Proc. 2015;6:506-16.

14. Chang A, Jung J, Maeda MM, Landivar J. Crop height monitoring with digital imagery from Unmanned Aerial System (UAS). Comput Electron Agric. 2017;141:232-7.

15. Watanabe K, Guo W, Arai K, Takanashi H, Kajiya-Kanegae H, Kobayashi $M$, et al. High-throughput phenotyping of sorghum plant height using an unmanned aerial vehicle and its application to genomic prediction modeling. Front Plant Sci. 2017:8:421.

16. Chang A, Eo Y, Kim S, Kim Y, Kim Y. Canopy-cover thematic-map generation for Military Map products using remote sensing data in inaccessible areas. Landsc Ecol Eng. 2011;7(2):263-74.

17. Khan Z, Chopin J, Cai J, Eichi VR, Haefele S, Miklavcic SJ. Quantitative estimation of wheat phenotyping traits using ground and aerial imagery. Remote Sens. 2018;10(6):950.

18. Anthony D, Elbaum S, Lorenz A, Detweiler C. On crop height estimation with UAVs. In: IEEE international conference on intelligent. robots and systems. 2014. p. 4805-12.

19. Rey-Caramés C, Diago MP, Pilar Martín M, Lobo A, Tardaguila J. Using RPAS multi-spectral imagery to characterise vigour, leaf development, yield components and berry composition variability within a vineyard. Remote Sens. 2015;7(11):14458-81.

20. Radoglou-Grammatikis P, Sarigiannidis P, Lagkas T, Moscholios I. A compilation of UAV applications for precision agriculture. Comput Netw. 2020;172:107148.

21. Lottes P, Khanna R, Pfeifer J, Siegwart R, Stachniss C. UAV-based crop and weed classification for smart farming. In: Proceedings of the IEEE international conference on robotics and automation. 2017; p. 3024-31.

22. Song $Y$, Wang J. Winter wheat canopy height extraction from UAVbased point cloud data with a moving cuboid filter. Remote Sens. 2019;11(10):1239.

23. Borra-Serrano I, De ST, Quataert P, Aper J, Saleem A, Saeys W, et al. Closing the phenotyping gap: High resolution UAV time series for soybean growth analysis provides objective data from field trials. Remote Sens. 2020;12(10):1644.

24. Uto K, Seki H, Saito G, Kosugi Y, Zarco-Tejada PJ, González-Dugo V, et al. Combining UAV-based plant height from crop surface models, visible, and near infrared vegetation indices for biomass monitoring in barley. IEEE J Sel Top Appl Earth Obs Remote Sens. 2013;39:79-87.

25. Jimenez-Berni JA, Deery DM, Rozas-Larraondo P, Condon ATG, Rebetzke GJ, James RA, et al. High throughput determination of plant height, ground cover, and above-ground biomass in wheat with LiDAR. Front Plant Sci. 2018;9:237.

26. Ten Harkel J, Bartholomeus H, Kooistra L. Biomass and crop height estimation of different crops using UAV-based LiDAR. Remote Sens. 2020;12(1):17.
27. Schirrmann M, Hamdorf A, Giebel A, Gleiniger F, Pflanz M, Dammer KH. Regression kriging for improving crop height models fusing ultra-sonic sensing with UAV imagery. Remote Sens. 2017;9(7):665.

28. Thompson A, Thorp K, Conley M, Elshikha D, French A, AndradeSanchez $\mathrm{P}$, et al. Comparing nadir and multi-angle view sensor technologies for measuring in-field plant height of upland cotton. Remote Sens. 2019;11(6):700.

29. Belton D, Helmholz P, Long J, Zerihun A. Crop height monitoring using a consumer-grade camera and UAV technology. PFG J Photogramm Remote Sens Geoinf Sci. 2019;87(56):249-62.

30. Tirado SB, Hirsch CN, Springer NM. UAV-based imaging platform for monitoring maize growth throughout development. Plant Direct. 2020:7:4213.

31. Hassan MA, Yang M, Fu L, Rasheed A, Zheng B, Xia X, et al. Accuracy assessment of plant height using an unmanned aerial vehicle for quantitative genomic analysis in bread wheat. Plant Methods. 2019;15(1):1-12.

32. Volpato L, Pinto F, González-Pérez L, Thompson IG, Borém A, Reynolds $\mathrm{M}$, et al. High throughput field phenotyping for plant height using UAVbased RGB imagery in wheat breeding lines: feasibility and validation. Front Plant Sci. 2021;12:185.

33. Liu H, Zhang J, Pan Y, Shuai G, Zhu X, Zhu S. An efficient approach based on UAV orthographic imagery to map paddy with support of field-level canopy height from point cloud data. IEEE J Sel Top Appl Earth Obs Remote Sens. 2018;11:2034-46.

34. Yang CY, Yang M Der, Tseng WC, Hsu YC, Li GS, Lai MH, et al. Assessment of rice developmental stage using time series uav imagery for variable irrigation management. Sensors (Switzerland). 2020; 1-21.

35. Hu P, Chapman SC, Wang X, Potgieter A, Duan T, Jordan D, et al. Estimation of plant height using a high throughput phenotyping platform based on unmanned aerial vehicle and self-calibration: example for sorghum breeding. Eur J Agron. 2018;95:24-32.

36. Han X, Thomasson JA, Bagnall GC, Pugh NA, Horne DW, Rooney WL, et al. Measurement and calibration of plant-height from fixed-wing UAV images. Sensors (Basel). 2018;18(12):4092.

37. Falco N, Wainwright HM, Dafflon B, Ulrich C, Soom F, Peterson JE, et al. Influence of soil heterogeneity on soybean plant development and crop yield evaluated using time-series of UAV and ground-based geophysical imagery. Sci Rep. 2021;11(1):1-17.

38. Han L, Yang G, Dai H, Yang H, Xu B, Feng $H$, et al. Fuzzy clustering of maize plant-height patterns using time series of UAV remote-sensing images and variety traits. Front Plant Sci. 2019;10:926.

39. Holman FH, Riche AB, Michalski A, Castle M, Wooster MJ, Hawkesford MJ. High throughput field phenotyping of wheat plant height and growth rate in field plot trials using UAV based remote sensing. Remote Sens. 2016;8(12):1031.

40. Demir N, Sönmez NK, Akar T, Ünal S. Automated Measurement of plant height of wheat genotypes using a DSM derived from UAV imagery. Proceedings [Internet]. 2018; 2:350. http://www.mdpi.com/2504-3900/2/ $7 / 350$

41. Jin $X, L i$ Z, Yang G, Yang H, Feng $H$, Xu X, et al. Winter wheat yield estimation based on multi-source medium resolution optical and radar imaging data and the AquaCrop model using the particle swarm optimization algorithm. ISPRS J Photogramm Remote Sens. 2017;126:24-37.

42. Tao H, Feng $H, X u L$, Miao M, Yang G, Yang X, et al. Estimation of the yield and plant height of winter wheat using UAV-based hyperspectral images. Sensors (Switzerland). 2020;20(4):1231.

43. Gilliot JM, Michelin J, Hadjard D, Houot S. An accurate method for predicting spatial variability of maize yield from UAV-based plant height estimation: a tool for monitoring agronomic field experiments. Precis Agric. 2021;22(3):897-921.

44. Feng L, Zhang Z, Ma Y, Du Q, Williams P, Drewry J, et al. Alfalfa yield prediction using UAV-based hyperspectral imagery and ensemble learning. Remote Sens. 2020;12(12):2028.

45. Sun C, Feng L, Zhang Z, Ma Y, Crosby T, Naber M, et al. Prediction of end-of-season tuber yield and tuber set in potatoes using in-season uavbased hyperspectral imagery and machine learning. Sensors (Switzerland). 2020;20(18):5293. 
46. Thapa S, Zhu F, Walia H, Yu H, Ge Y. A novel LiDAR-based instrument for high-throughput, 3D measurement of morphological traits in maize and sorghum. Sensors. 2018;18(4):1187.

47. Hosoi F, Nakabayashi K, Omasa K. 3-D modeling of tomato canopies using a high-resolution portable scanning lidar for extracting structural information. Sensors. 2011;11(2):2166-74.

48. Yu D, Zha Y, Shi L, Jin X, Hu S, Yang Q, et al. Improvement of sugarcane yield estimation by assimilating UAV-derived plant height observations. Eur J Agron. 2020;121:126159.

49. Fu H, Wang C, Cui G, She W, Zhao L. Ramie yield estimation based on UAV RGB images. Sensors (Switzerland). 2021;21(2):669.

50. Dash JP, Watt MS, Pearse GD, Heaphy M, Dungey HS. Assessing very high resolution UAV imagery for monitoring forest health during a simulated disease outbreak. ISPRS J Photogramm Remote Sens. 2017;131:1-14.

51. Fisher JRB, Acosta EA, Dennedy-Frank PJ, Kroeger T, Boucher TM. Impact of satellite imagery spatial resolution on land use classification accuracy and modeled water quality. Remote Sens Ecol Conserv. 2018;4(2):137-49.

52. Tilly N, Hoffmeister D, Cao Q, Huang S, Lenz-Wiedemann V, Miao Y, et al. Multitemporal crop surface models: accurate plant height measurement and biomass estimation with terrestrial laser scanning in paddy rice. J Appl Remote Sens. 2014;8(1):083671.

53. Yin X, McClure MA, Jaja N, Tyler DD, Hayes RM. In-season prediction of corn yield using plant height under major production systems. Agron J. 2011;103(3):923-9.

54. Geipel J, Link J, Claupein W. Combined spectral and spatial modeling of corn yield based on aerial images and crop surface models acquired with an unmanned aircraft system. Remote Sens. 2014;6(11):10335-55.

55. Stanton C, Starek MJ, Elliott N, Brewer M, Maeda MM, Chu T. Unmanned aircraft system-derived crop height and normalized difference vegetation index metrics for sorghum yield and aphid stress assessment. J Appl Remote Sens. 2017;11(2):026035.

56. Crane-Droesch A. Machine learning methods for crop yield prediction and climate change impact assessment in agriculture. Environ Res Lett. 2018;13(11):114003

57. Guo Y, Wang H, Wu Z, Wang S, Sun H, Senthilnath J, et al. Modified red blue vegetation index for chlorophyll estimation and yield prediction of maize from visible images captured by UAV. Sensors (Switzerland). 2020;20(18):5055.

58. Bai T, Sun K, Deng S, Li D, Li W, Chen Y. Multi-scale hierarchical sampling change detection using Random Forest for high-resolution satellite imagery. Int J Remote Sens. 2018;39:7523-46. https://doi.org/10.1080/ 01431161.2018 .1471542$.

59. Ali MM, Mrithyumjaya RSNK. An overview of recent and traditional decision tree classifiers in machine learning. Int J Res Rev Ad hoc Netw. 2011;1(1):9-16.

60. Sun $G$, Wang $X$, Yang $H$, Zhang $X$. A canopy information measurement method for modern standardized apple orchards based on UAV multimodal information. Sensors (Switzerland). 2020;20(10):2985.

61. Zhou G, Bao X, Ye S, Wang H, Yan H. Selection of optimal building facade texture images from UAV-based multiple oblique image flows. IEEE Trans Geosci Remote Sens. 2021;59(2):1534-52.

62. Cao JS, Deng ZY, Li W, Hu YD. Remote sensing inversion and spatial variation of land surface temperature over mining areas of Jixi, Heilongjiang, China. PeerJ. 2020;8:e10257.

63. Song Z, Zhang Z, Yang S, Ding D, Ning J. Identifying sunflower lodging based on image fusion and deep semantic segmentation with UAV remote sensing imaging. Comput Electron Agric. 2020;179:105812.

64. Cherkassky V, Ma Y. Practical selection of SVM parameters and noise estimation for SVM regression. Neural Netw. 2004;17(1):113-26.

65. Fei S, Hassan MA, He Z, Chen Z, Shu M, Wang J, et al. Assessment of ensemble learning to predict wheat grain yield based on UAV-multispectral reflectance. Remote Sens. 2021;13(12):2338.

66. Yang S, Hu L, Wu H, Ren H, Qiao H, Li P, et al. Integration of Crop Growth Model and Random Forest for Winter Wheat Yield Estimation from UAV Hyperspectral Imagery. IEEE J Sel Top Appl Earth Obs Remote Sens. 2021;14:6253-69.

67. Yue J, Feng H, Yang G, Li Z. A comparison of regression techniques for estimation of above-ground winter wheat biomass using near-surface spectroscopy. Remote Sens. 2018;10(2):66.

\section{Publisher's Note}

Springer Nature remains neutral with regard to jurisdictional claims in published maps and institutional affiliations.
Ready to submit your research? Choose BMC and benefit from:

- fast, convenient online submission

- thorough peer review by experienced researchers in your field

- rapid publication on acceptance

- support for research data, including large and complex data types

- gold Open Access which fosters wider collaboration and increased citations

- maximum visibility for your research: over 100M website views per year

At BMC, research is always in progress.

Learn more biomedcentral.com/submissions 